Marek Cybulski

Uniwersytet Łódzki

Katedra Historii Języka Polskiego

\title{
O RZADKICH ŚREDNIOPOLSKICH FORMACH ADRESATYWNYCH
}

Obok standardowych form adresatywnych, które występują w niemal wszystkich wypowiedziach dialogowych mówionych i pisanych, używane są często i w różnorodnych sytuacjach, trafiają się i takie, które z różnych przyczyn mają niską frekwencję tekstową. Dawne polskie niewołaczowe ${ }^{1}$ formy standardowe były przedmiotem obserwacji Geralda Stone'a, który przedstawił zwięźle ich historię od czasów najdawniejszych do wieku XVIII [1984, s. 45-56; 1985, s. 55-66; 1989, s. 135-142]. W niniejszej pracy uzupełniamy jego materiały o formy rzadko w dawnych tekstach spotykane. Są tu trzy główne typy form.

\section{ZAIMEK DZIERŻAWCZY + NAZWA CECHY NA -OŚĆ}

Po pierwsze, mamy formy, w których rzeczownik abstrakcyjny jest inny niż miłość. Większość zapisów pochodzi z XVI wieku, kiedy nie ustaliła się jeszcze zdecydowana przewaga połączeń z tym rzeczownikiem. Formy Wasza Jasność użył biskup witając królową w jednej z najstarszych polskich oracji z roku 1510:

Ksiądz biskup [...] Waszę Jasność przywita[j]e [...]. Jasności Waszej przyjechanie [...] Wasza Jasność teże nie będzie raczyła być [...] Wasza Jasność [...] nie racz (Vrtel 453).

Do urzędników szlacheckich, którym oficjalnie przysługiwał epitet urodzony, pisać można było Urodzoność Twoja. Rej tak napisał w dedykacji staroście:

Urodzoność Twa znam [...] nie do kogo inego napisać, jedno do Urodzoności Twojej (RejŹwierc 2, 150; sim. ib. 151).

1 Tzn. zintegrowane składniowo, będące składnikami zdań. 
Z kolei per Wasza Laska i Wasza Stawetność zwracali się mieszczanie do mieszczan, czyli „łaskawi” i „sławetni” do „łaskawych” i „sławetnych” (być może do zbiorowości) - jeden przykład znalazł się w XVI-wiecznym liście i jeden w późniejszej komedii:

nasze zrządzenie Waszym Łaskam niniejszym tem to listem objawiame (1512, list rzeźników wrocławskich do krakowskich; Wyd 214-215, 216); siadajcie panowie! / To coś nowego pewnie wasza łaska powie (1622, Pan do Dziewosłęba; PKRyb 481); ku Waszym Sławetnościom (1560, dedykacja rajcom kazimierskim; Mrow 3; w tymże liście dwa razy zapisano zwykłe W.M. - przyp. M.C.).

Z epoki znacznie późniejszej pochodzi Prześwietność Wasza. Król August II zwrócił się tak w liście do prymasa:

czekamy [...] na przybycie Prześwietności Waszej (Ostr 4, 13).

Wszystkie pozostałe formy zaliczone do pierwszego typu to zapewne skrócenia standardowego niegdyś adresatywum wasza miłość.

Bardzo rzadko zapisywana (co nie znaczy, że rzadko używana), była forma Wasza Mość, o funkcji wskutek tego nie całkiem jasnej:

Co waszamość powiedasz? (1622, sługa do pana; PKRyb 480); tu się sam w sprawie mojej gotówem przed sądem Ich MMść Panów rozprawić z w[a]sza Mść Panie Sopoćko (1648; Pocz rkp za SłXVII); Proszę waszej mości, / Jedźcie precz (z Wirydarza poetyckiego Trembeckiego; PPB 2, 595); Miej wasza mość nad nami swe politowanie (1670, chłop do szlachcica; PPB 2, 595; 733); Pokornie proszę Waszychmościów, abyście jedli (Mich 123); w czymkolwiek zasię Pan młody [...] będzie mógł waszychmościom odsłużyć (na weselu mieszczańskim; PPB 2, 221)

- ostatni zapis świadczy o unieruchomieniu pierwszego członu formuły.

Niewielka liczba zapisów wyrazu Waszność pochodzi głównie z przełomu wieków XVI i XVII. Waszność (lub wasność z mazurzeniem) ma wyraźnie konwersacyjny i plebejski charakter. Zwracano się tak do kogoś wyżej usytuowanego w społecznej hierarchii. Zazwyczaj łączono tę formę z orzeczeniem w liczbie mnogiej:

jeśli wasność chcecie (1590, przekupień do plebana; ALSow 13); dajcie wasność złotych ze dwieście ALSow 22; nie rzekłbyś też wasność [...]. Bodajże waszność zdrów był (1590, handlarz do plebana; ALSow 31); Nędza ich też ze szkoły waszności wygnała (1615, chłop do żołnierza; ALSow 100); Panie doktorze [...] / Dajcie receptę [...], / Boście wy, wasność ${ }^{2}$, urynał ćwicony. [...] Mnieć srom wasności [...] Jeśli mi zgoła wasność nie wierzycie (po 1615, chłop do lekarza; PFM 253); Mości Dobrodzieju, powinieneś mi waszność świadczyć łaskę (XVII w., ksiądz mieszczańskiego pochodzenia do biskupa; DawFac 469).

2 Zestawienia form wy i wasność w jedną formułę autor dokonał chyba dla ośmieszenia postaci jako nieznającej funkcji form grzecznościowych. 
W XVIII wieku pojawił się wyraz Wać o funkcji niełatwej do określenia. Używano go w różnych sytuacjach, zwracając się do niższego, wyższego i do równego sobie:

wać i sukni poczciwej nie masz [...] daj wać jemu sześćdziesiąt cynowych złotych (książę do swych dworzan; Żera 203); Co wać tu robisz? [...] Idź wać sobie (Żyd do zakonnika; Żera 229); Żeby wać mi jego darmo dawał (Żyd do sługi klasztornego; Żera 231); lepiej się Wać mylisz (rozmowa szlachciców; Małp 239).

Być może regionalnie i socjalnie ograniczone do mieszczaństwa (małopolskiego?) były wyrazy Waśnić, Waśnieć itp. Dialog zawierający takie formy wydano zapewne w Krakowie (przypuszczenie Badeckiego - PSM 367):

Pani matko, idę do kościoła, / Raczże mię waśnić posłać (ok. 1684, córka do mieszczki; PSM 155); Nie mów waśnić tego; Jak się waśnici na zdrowiu powodzi (PSM 157); Niechajże tu z waśnicia dzisiaj będę spała [...] A snadź bym ja wolała i zdrowia samego / Postradać dla waśnici, dobrodzieja mego (do męża „słodziuchnymi słówki”; PSM 16233; z gołą rzycią / Pospołu z wasznicia / Dam wam zań grosz (PotOgr 2, 206; wg kartoteki SłXVII w tym miejscu wasniecia $)^{4}$.

Z kolei Mazowszu przypisywano wyrazy Wasiść, Wasieść, składniowo łączące się zawsze z czasownikiem $\mathrm{w}$ lm.:

Pomagabóg, Bartoszu [...], / Jakoż sie wasiść macie (1613, rozmowa chłopów - Mazurów; PLM 63); A tak, wasiści prosę, raccie to wasiść opisać [...] Ale też wasiść naprzód była gorzałcyca [...] Było też wasiść piwko [...] raccie wasieść ze mną genalią gwazyć (po 1615, list do „piercy”, „Relacyja mazowiecka”; PFM 218).

Formy adresatywnej Waszoc użyła Kaszubka jako postać dramatu:

Dziękuję waszoc (1643, DrSt 6, 269-270).

W innym dramacie zwierzchnik zwraca się do duchownego protestanckiego per Waszość. Forma to zupełnie odosobniona, może jakiś wariant powyższej, używany na zachodzie Polski:

Trzeba ludzi na zamki, waszość się tam zgodzi (1617; PKRyb 275).

Także forma Wajeć (zapisywana wáieć, wáići) może stanowić jakiś zachodni regionalizm. Użył jej w swoich w rozmówkach Schlag. Wystąpiła w dialogach mieszczan:

3 Tamże znajdujemy derywat od tej formy, a mianowicie czasownik waśniciać 'używać formy waśnić': To chwali, to waśnicia, to jedwabne słówka / Sypie (PSM 161).

4 Jeszcze inny wariant odnotował BrSE 604, nie podając jednak źródła: nie pójdę za wasznic, bo wasznic nie masz nic. 
jakim towarem wajeć kupczysz (SchlN 162); racz wajeć do tej piwnice wstapić [...], tam waszeć dostaniesz juchtów, jak wiele ich wajeć potrzebujesz (SchlN 210; sim. ib. 211; 212; 213); teraz wajci drożej nie będzie trzeba płacić (SchlN 212).

Zapewne tylko w rozmowach zwracano się per Wasze. Niełatwo znaleźć zapisy takiej formy w dawnych tekstach, niełatwo też na podstawie nikłego materiału określić ściślej jej funkcję. Może nie jest przypadkiem, że w obu znalezionych przykładach mamy zwroty do księdza ${ }^{5}$ :

wasze patrem zową? (1632; PKRyb 509); ksiądz Piekarski: „Stój” - rzecze - zła nasza, panie bracie”. - Ja rzekę: „Panie bracie, pamiętajże Wasze, że w tej Wolskiego relacyjej połowy prawdy nie masz..." (Pas 123).

Geneza formy nie jest całkiem jasna. Zapewne wywodzi się ona z waszeć wskutek zaniku końcowej spółgłoski.

\section{RZECZOWNIKI PAN, PANI}

Formy adresatywne Pan, Pani, Państwo itd., wiążące się składniowo z czasownikiem w 3 os., powszechne i podstawowe dziś w polskiej etykiecie językowej, są zjawiskiem stosunkowo nowym. Dopiero na przełomie wieków XVII i XVIII pojawiają się teksty jasno świadczące, że nowa forma już istniała i że początkowo używana była przez ludzi niskiej kondycji w rozmowach z wyżej postawionymi. Jedno z wydań rozmówek (1696-1700) zawiera dialog mieszczki z robotnikiem, który mówi do niej per Pani:

- A co chcesz od rąbania? - Wszak Pani już wie. - Oto masz pieniądze. - Niech Pani przyda jeszcze z parę groszy (Mich 174-175).

Jest to zapis znacznie wcześniejszy niż znaleziony w korespondencji z roku 1766 przez G. Stone'a i znany mu jako pierwszy zaświadczony [1989, s. 136].

Dość częste są nowe formy w osiemnastowiecznym zbiorku anegdot Karola Żery. Niektóre zapisy poświadczają użycie 3 os., jak np. przez chłopa w rozmowie ze szlachcicem:

A na cóż się pan pyta (Żera 222).

W innych dialogach występuje oboczność 2 i 3 os. czasownika:

Pan czy jedziesz (Żera 47); dobrze, że pan jedzie (Żera 47); pan i sam się na pojeździe $z b i$ jesz (Żera 47), Czy pamiętasz to pan? (szlachcic do szlachcica; Żera 69); Co by pan w takim przypadku robit? (szlachcic do szlachcica; Żera 109).

5 Jeszcze na początku XX w. chłopi natrząsali się z drobnej szlachty mazowieckiej powiedzonkami: Pódź wase na kase, Myślis wase, ze wase jest wase, a to wase nie wase, tylo wase ty itp. NKPrzysł 3, 623-624. 
Zdaniem G. Stone'a, formy niewokatywne Pan, Pani, wiążące się składniowo $\mathrm{z}$ czasownikiem w 3 os., są wynikiem maksymalnego uproszczenia rozbudowanych substytutów nominalnych typu waszmość pan [Stone, 1989, s. 140]. Wydaje się jednak, że geneza tych form przedstawia się inaczej. Istotną rzeczą jest tu składnia, a mianowicie wiązanie się najstarszych form adresatywnych pan, pani z 3 os. czasownika, podczas gdy standardowe formy typu waćpan wymagały 2 os. Odmienność składni wskazuje na odmienność genezy obu typów adresatywów, nie zaś na przejście jednego w drugi [zob. Cybulski, 1994, s. 36]. Pan jako adresatywum wywodzi się zatem nie ze starszych adresatywów, lecz z form określających osobę trzecią.

Jeśli zaś idzie o socjolingwistyczną funkcję nowej formy, to już Jan Łoś [1916, s. 8] zauważył, że w osiemnastowiecznych komediach służba do swoich chlebodawców zwracała się per pan. Jest też o tym wzmianka u Stone'a [1989, s. 137], obaj autorzy nie przywiązywali jednak szczególnej wagi do tego spostrzeżenia. Tymczasem w świetle powyższego materiału jasne jest, że form nowych używali pierwotnie plebejusze, zwracając się do wyżej postawionych, słudzy do panów itp. [zob. Cybulski, 1994, s. 37]. Byłby to jeden z przykładów wpływu niższych sfer społecznych na postać polskiej etykiety językowej6.

\section{ZAIMEK ANAFORYCZNY}

Z punktu widzenia funkcji jest to forma dość dziwna jako (diachronicznie rzecz ujmując) substytucja pronominalna substytucji nominalnej zaimka. Zaimek anaforyczny w funkcji adresatywnej (najpierw on, potem najczęściej przypadki zależne jego itd.) to cecha polszczyzny epistolograficznej, nie wcześniejsza niż z drugiej połowy XVII wieku. Najstarsze użycie trudno uznać za uprzejme, bo wystapiło w liście z pogróżkami, który hetman Doroszenko wysłał do załogi Lwowa:

Zatym się przyjaźni onych pilno polecam (1667) Bar 73.

Ale już od końca wieku XVII zaimek on należy do epistolarnych sygnałów grzeczności:

każde szczęśliwości osoby WKMści są mi pociechą i szczęściem, a rozkazanie Onegoż honorem (1690, marsz. w. kor. do królewicza; Ostr 4, 78); obowiązywać jako najściślej uprzejmości i wierności wasze i onym pilno zalecić (1744, uniwersał króla; Ostr 3, 30).

6 Nie bierzemy tu pod uwagę przymiotnika pański w kontekstach takich jak formuły listowe typu Do nóg pańskich nizusieńko upadam jak najniższy sługa. Funkcja adresatywna nie jest tu pewna. 
Zaimek jego, jemu itp. pojawił się i powoli upowszechnił w tej funkcji na początku XVIII wieku, może dlatego, że formuły epistolarne stały się wówczas zbyt długie, by je stale w tekście powtarzać:

Panerując rekwizycyjej Wmm Pana [...] siebie nieodmiennemi Jego rekomendując afektowi (1705, hetman zaporoski do hetmana kor.; Maz 47); Uznawszy dobroczynną łaskę JOWKsMości Dobrodzieja [...] poważam się suplikować z upadnieniem do nóg Jego (1737; Drużb 30); do uszczęśliwienia interesów [...] WksMści obligowany, tak na wszelkie Jej rozkazy zapisuję się ochotnym (1737, marszałek nadw. kor. do księżnej; AKr 4, 48); konkluduję wolność dziękczynienia subiekcyją powinną superioribus et distinctis J.W. WMWMPana, rekomenduję się pamięci i respektom Jego na zawsze (1744, kasztelan do kanclerza; Ostr 4, 102); u stóp Jego Książęcych (1750, do stryja; KRadz 10).

W tymże okresie zalecano też takie formy w rozmowach etykietalnych:

Żegnam go tedy cum gratiarum actione za Pańskie jego łaski, najniższe oświadczając dzięki (gość do gospodarza; Bystrz 111).

Na koniec spróbujemy odpowiedzieć na pytanie, jakie mogą być przyczyny tego, że pokazane tu formy adresatywne miały niską frekwencję w tekstach średniopolskich. Dadzą się, jak sądzę, wyróżnić cztery czynniki mające na to wpływ: czynnik chronologiczny, czynnik geograficzny, czynnik społeczny i czynnik tekstowy (gatunkowy).

Zależność chronologiczna ujawnia się dwojako. Po pierwsze: forma jest rzadka, bo poświadczona zapewne przez resztki stanu panującego wcześniej, tj. w średniowieczu i w początkach XVI wieku. Można przypuszczać, że była to forma niegdyś częsta, ale w XVI wieku już wymierająca. To by dotyczyło np. Waszej Jasności i Waszej Urodzoności. Po drugie: w początkach XVIII wieku mogło być tak, że dana forma dopiero się rodziła i później dopiero, w dobie nowopolskiej, upowszechniła się i zyskała rangę standardowej. To by dotyczyło np. form Pan, Pani i zaimka anaforycznego.

Zależność geograficzna mogła się nakładać na społeczną, co przejawiało się ograniczeniem użycia danej formy do takiego regionu (np. Mazowsza), do takich warstw społecznych (np. ludowych) i do takich mówionych odmian polszczyzny (np. gwar), które nie miały szans na szersze pokazanie się w piśmiennictwie, bo te regiony, warstwy i odmiany mało ceniono lub nawet pogardzano nimi. To by dotyczyło np. form Waszność, Waśnić, Wasiść, Wajeć, Waszoc, początkowo też form Pan i Pani.

Zależność tekstowa (gatunkowa) niskiej frekwencji polegała na tym, że niektórych form używano w codziennych, potocznych rozmowach, które z natury rzeczy nie miały odpowiedniej reprezentacji w piśmiennictwie. Jeśli znajdu- 
jemy takie formy (np. Wasza Mość i Wasze) w tekstach pisanych, to głównie w literackich przetworzeniach rozmów, jak podlegające swoistym konwencjom gatunkowym komedie i dialogi.

\section{ROZWIĄZANIA SKRÓTÓW}

AKr - Akta sejmikowe województwa krakowskiego, t. 4: 1674-1680, 1963-1964, wyd. A. Przyboś, Kraków.

ALSow - Antologia literatury sowizdrzalskiej XVI i XVII wieku, 1985, oprac. S. Grzeszczuk, wyd. 2, Warszawa.

Bar - BARĄCz Sadok, Pamiętnik dziejów polskich z aktów urzędowych lwowskich i z rękopismów..., Lwów 1855.

Bystrz - Bystrzonowski Wojciech, 1737, Polak sensat w liście, w komplemencie polityk, humanista $\mathrm{w}$ dyskursie, w mowach statysta..., Lublin.

DawFac - Dawna facecja polska (XVI-XVII w.), 1960, oprac. J. Krzyżanowski i K. Żukowska-Billip, Warszawa.

DrSt - Dramaty staropolskie. Antologia, 1959-1963, oprac. J. Lewański, t. 1-6, Warszawa.

Drużb - MarczewsKa-StaŃDowa Elżbieta, 1960, Listy Elżbiety Drużbackiej, „Archiwum Literackie”, 5, s. 19-51.

KRadz - Korespondencja księcia Karola Stanisława Radziwiłła wojewody wileńskiego „Panie Kochanku” 1744-1790 z archiwum w Werkach, 1898, wyd. C. Jankowski, Kraków.

Małp - Małpa - człowiek w cnotach, obyczajach i kroju, 1962, wyd. P. Buchwaldówna, „Archiwum Literackie”, 6, Wrocław, s. 163-330.

Maz $\quad-$ On the Eve of Poltava: The Letters of Ivan Mazepa to Adam Sieniawski, 1704-1708, 1975, wyd. O. Subtelny, New York.

Mich - Michael Petrus, ok. 1696-1700, Der richtige Wegweiser oder eine gründliche Anleitung zur polnischen Sprache..., Toruń.

Mrow - Mrowiński Jan, 1890, Płoczywłos, Stadło małżeńskie. 1561, wyd. Z. Celichowski, Kraków.

NKPrzysł - Nowa księga przysłów i wyrażeń przysłowiowych polskich, 1972, w oparciu o dzieło Samuela Adalberga opracował Zespół Redakcyjny pod kierunkiem J. Krzyżanowskiego, t. 3: R-Ż, Warszawa.

Ostr - Ostrowski-DANeJKowicz Jan, 1745, Swada polska i łacińska albo miscellanea oratorskie sejmowe, weselne, kancelaryjne, listowne, kaznodziejskie, pogrzebowe..., t. 1-6, Lublin. 
Pas - Pasek Jan, 1955, Pamiętniki, oprac. R. Pollak, Warszawa.

PFM - Polska fraszka mieszczańska. Minucje sowiźrzalskie, 1948, wyd. K. Badecki, Kraków.

PKRyb - Polska komedia rybałtowska, 1931, oprac. K. Badecki, Lwów.

Pocz - Poczobut-Odlanicki Jan Władysław, 1987, Pamiętnik, oprac. A. Rachuba, Warszawa.

PotOgr - Pотоскі Wacław, 1907, Ogród fraszek, wyd. A. Bruckner, t. 1-2, Lwów.

PPB - Poeci polskiego baroku, 1965, oprac. J. Sokołowska, K. Żukowska, t. 1-2, Warszawa.

PSM - Polska satyra mieszczańska. Nowiny sowiźrzalskie, 1950, wyd. K. Badecki, Kraków.

RejŹwierc - REs Mikołaj, Źwierciadło albo kstałt, w którym każdy stan snadnie się może swym sprawam, jako we źwierciedle, przypatrzyć, 1914, wyd. J. Czubek i J. Łoś, Kraków.

SchlN - Schlag Georg, 1745, Neunundfünfzig polnisch-deutsche Handlungsgespräche..., Wrocław.

SłXVII - Słownik polszczyzny XVII i pierwszej połowy XVIII wieku, kartoteka Instytutu Języka Polskiego PAN.

Vrtel - VRTEL-WierCZYŃSKi Stefan, 1969, Wybór tekstów staropolskich. Czasy najdawniejsze do r. 1543, wyd. 4, Warszawa.

Wyd - Wydra Wiesław, Rzepka Wojciech Ryszard, 1984, Chrestomatia staropolska. Teksty do roku 1543, Wrocław.

Żera $\quad-$ ŻerA Karol, 1980, Vorago rerum Torba śmiechu Groch z kapustą A każdy pies z innej wsi..., oprac. K. Żukowska, Warszawa.

\section{BIBLIOGRAFIA}

Cybulski Marek, 1994, Pan i sługa. Niektóre społeczne uwarunkowania zmian w polskich obyczajach językowych, w: Uwarunkowania i przyczyny zmian językowych. Zbiór studiów, red. Elżbieta Wrocławska, Warszawa, s. 31-39. Łoś Jan, 1916, Od ty do pan, „Język Polski”, 3, s. 1-10.

StONE Gerald, 1989, Formy adresatywne języka polskiego w osiemnastym wieku, „Język Polski”, 69, s. 135-142.

Stone Gerald, 1984, Honorific Pronominal Address in Polish Before 1600, „Oxford Slavonic Papers", New Series XVII, s. 45-56.

Stone Gerald, 1985, Polish Pronominal Address in the Sevetheeth Century, „Oxford Slavonic Papers”, New Series XVIII, s. 55-66. 